\title{
Locating the Parenting Style in Indian Context: The Emerging Themes
}

\author{
Himani Verma \\ Teach for India, Tata Institute of Social Sciences, Mumbai, India \\ Email: himani.verma2017@teachforindia.org
}

\begin{abstract}
Socialization has been carried out due to the agency of the parents (Schaffer, 1996), it is a process that molds a child into the culture of its group thereby making the child an accepted member of the society (Dunham, 1957). Ongoing changes in terms of demographic and social factors in India are acting as a catalyst for significantly increasing variation in the multiplicity of Indian families and child-rearing practices (Sahithya, Manohari, \& Vijaya, 2019). Ongoing changes in terms of demographic and social factors in India are acting as a catalyst for significantly increasing variation in the multiplicity of Indian families and child-rearing practices (Sahithya, Manohari, \& Vijaya, 2019). In traditional conventional Indian family fathers are usually portrayed as distant and aloof whereas mothers take the role of a nurturant concerning parenting. Parental practices are subjected to change with change in the social and demographic location of a family.
\end{abstract}

Keywords: Socialization; Disciplinary; Demographic; Parenting; Indian; Child.

Socialization has been carried out due to the agency of the parents (Schaffer, 1996), it is a process that molds a child into the culture of its group thereby making the child an accepted member of the society (Dunham, 1957). Culture specifies the goals of socialization (Jacob \& Seshadri, 2013) and kind of parenting practices likely to be employed by the parents in compliance with the norms practiced in the culture wherein the child was born (Sinha, 1981) thus influencing the ideal developmental goals for the parents (Sahithya, Manohari, \& Vijaya, 2019).

Parenting style constitutes behavior that is consistent with the culture that parents take on to manage their child, which varies based on their priorities as a parent and the attitude they hold towards certain things, as indicated by a research, the parenting style of the mother in the same culture differs based on the value she placed on certain aspect i.e the mothers who regarded "respect towards elder" and "family honor" used authoritarian style in comparison to mothers who were more authoritative in her style valued socio-emotional development of the child (Rao, McHale, \& Pearson, 2003; Sahithya, Manohari, \& Vijaon ya, 2019). Contemporary literature available on parenting styles and disciplinary practices in the context of socialization has based their work on Baumrind (1971) three types of parenting style: authoritarian, authoritative, and permissive, where permissive parenting was further dissected by Maccoby and Martin (1983) into uninvolved parenting style.

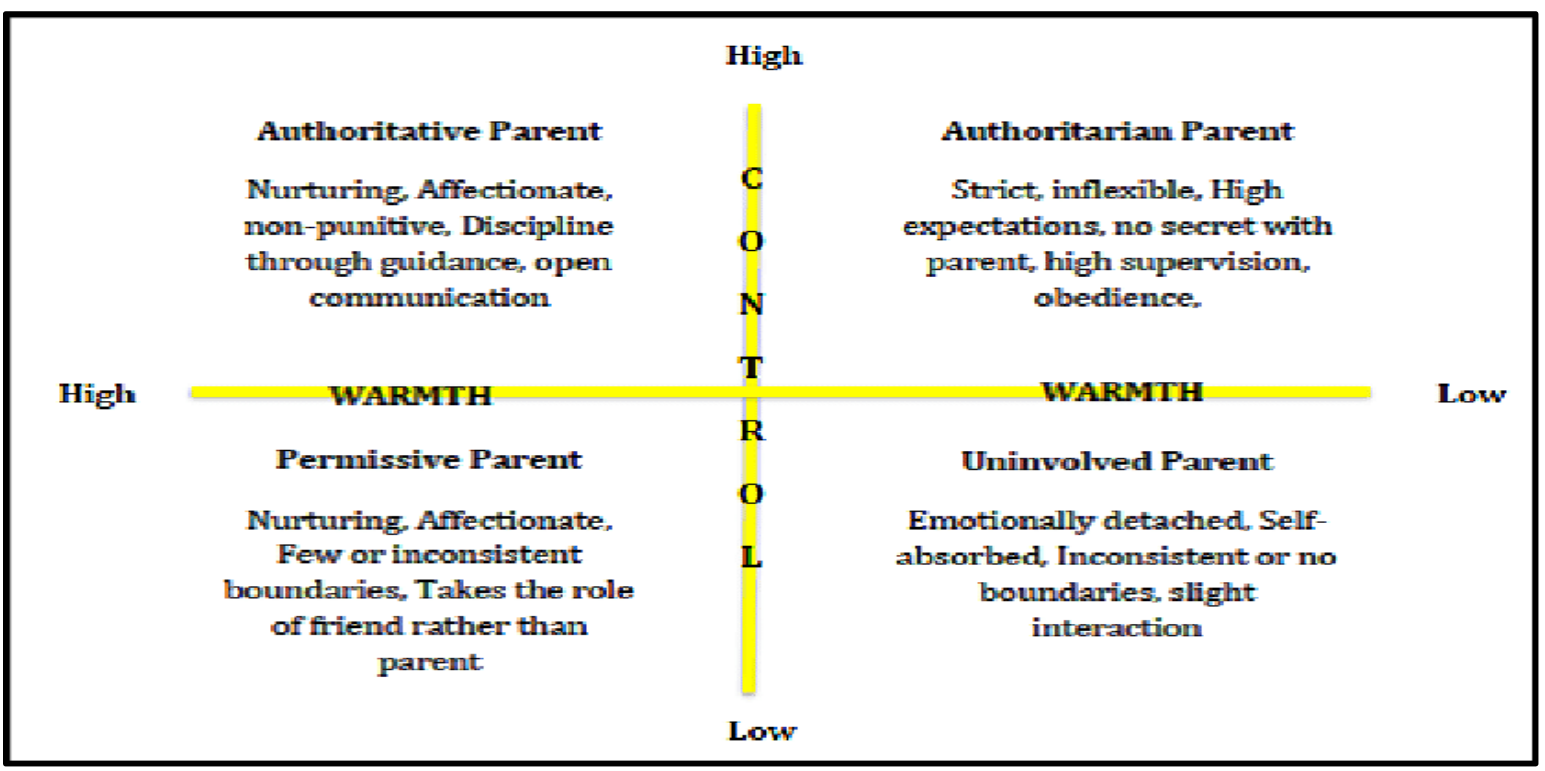

Figure 1: Parenting Style. 
Ongoing changes in terms of demographic and social factors in India are acting as a catalyst for significantly increasing variation in the multiplicity of Indian families and childrearing practices (Sahithya, Manohari, \& Vijaya, 2019). While comparing the parenting style in West with Asian cultures the key difference in their styles lies in their appraisal on independence and/or interdependence' while parenting style in west promotes individualism, competitiveness, and selfsufficiency the parenting style in Asia stress more on compliance, orthodoxy and social interdependence (Keller \& Otto, 2009). The major themes for exploring the socialization of a child in a family (focusing on India) while noting parenting styles and disciplinary patterns can revolve around; parent-child bond, gender difference, variation in mother-father practice, and social \& demographic location.

Breast-feeding, cuddling, and body massage are some of the child-rearing practices that invite for building a parent-child bond which results in a sense of security due to an increase in physical and emotional contact between a mother and a child. Studies have shown that 59.9\% (Patel et. al, 2015) of children in India are breastfed for the first six months in comparison to $24.9 \%$ in the US (CDC, 2018). Practices such as sharing a bed with a child (up to childhood) are common in Indian families whereas in West even infants are given a separate room.

Gender roles are institutionalized and embedded in everyday language and cultural practices in India. One can commonly see differences in parenting style and disciplinary practices taking gender as a factor indicating a gender difference in the socialization of a child and variation in mother-father's practice.

A study conducted by K. Vyas \& S. Bano, 2016 showed a significant difference in mothers with an authoritative parenting style concerning sons and daughters whereas there was no significant difference between authoritarian mother's parenting style concerning sons and daughters whereas concerning father's style daughters experienced more positive parenting. In another study conducted by Pander \& Kumar, 2009 it was indicated that for a female child father had shown emotional warmth whereas for a male child he displayed a rejecting behavior. In a study conducted by Natarajan, 2010; Shalini \& Acharya, 2013 it was shown that female college students perceived their parents as authoritative which was contrasting with male college student's perception. These studies indicate the difference in a parental style influenced by the gender of a child.

In traditional conventional Indian family fathers are usually portrayed as distant and aloof whereas mothers take the role of a nurturant concerning parenting. In a recent compilation and review of research by Sriram, 2019 in her book 'Fathering in India: Images and Reality', shows how fathers in contemporary India are moving beyond such traditional notions and evolving to be active participants in childrearing practices. Concerning differences in parenting style and disciplinary practices between mothers and fathers, there was a difference in mother and father's parenting style where authoritative or permissive styles were more associated with mother's style and fathers acted as uninvolved or authoritarian (Barnhart et al. 2013). A study conducted by Sandhu and Sharma (2015) on 6-11-year-old girls indicated that authoritarian and uninvolved parenting style adopted by parents leads to social anxiety and social withdrawal in girls. On the other hand, one of the studies shows that a higher level of well-being among children was a result when there was a difference in who is being authoritative both parents or just the mother (Simons \& Conger, 2007).

The parents using the permissive style of parenting do not use overt means of exerting power pull off their means and ends rather they use to maneuver their child by reasoning (Baumrind, 1966) whereas parents who are authoritative guide their children in a reasonable manner where they appreciate both self-will and disciplinary confirmation which is usually guided by appropriate use of reinforcements and control (Baumrind, 1966; Baumrind, 1971). A study (Albert et al., 2007) showed children indicated less avoidance and anxiety when there is a high use to control as a disciplinary practice by an Indian mother in contrast to this another studied showed an association between a high level of control exhibited by a mother with factors like anxiety, stress, and depression where one of the variable 'gender' was a creating a difference in result concerning aggression in girls high level of control lead to it whereas in boys less degree of control leads to aggression (Johal \& Kaur, 2015). 
Parental practices are subjected to change with change in the social and demographic location of a family. A recent review of studies conducted by Sahithya, Manohari, \& Vijaya, 2019 shows that there is a shift towards nurturing, autonomy granting authoritative styles that are less controlling and punitive when it comes to catering to child's need in an urbanized nuclear family.

\section{REFERENCES}

[1] Albert, I., Trommsdorff, G., \& Mishra, R. (2007). Parenting and adolescent attachment in India and Germany. In Z. Guanying (Ed.), Perspectives and progress in contemporary cross-cultural psychology (pp. 97-108). Beijing: China Light Industry Pr.

[2] Baker, M. (2014). Definitions, Cultural Variations, and Demographic Trends. In M. Baker, Choices and Constrains in Family. Baumrind, D. (1966). Effects of Authoritative Parental Control on Child Behavior. Child Development, 37(4), 887-907. https://doi.org/10.2307/1126611

[3] Baumrind, D. (1971). Current patterns of parental authority. Developmental Psychology, 4(1, Pt.2), 1103. https://doi.org/10.1037/h0030372

[4] Baumrind, D. (1996, October). The Discipline Controversy Revisited. Family Relations, pp. 405-414. https://doi.org/10.2307/585170

[5] Barnhart, C. M., Raval, V. V., Jansari, A., \& Raval, P. H. (2013). Perceptions of parenting style among college students in India and the United States. Journal of Child and Family Studies, 22(5), 684- 693. https://doi.org/10.1007/s10826-012-9621-1

[6] Berk, L. (2007). Development through the lifespan. Allyn and Bacon.

[7] Bisht, S., \& Sinha, D. (1981). Socialization, Family and Psychological Diffrentitation . In D. Sinha, Socialization of Indian Child (pp. 41-52). New Delhi: Concept Publishing Company.

[8] CDC (Centers for Disease Control and Disease Prevention). (2018). Breastfeeding report card. Atlanta, GA: National Center for Chronic Disease Prevention and Health Promotion, U.S. Department of Health and Human services.

[9] Dunham, H. W. (1957). Methodology of Sociological Investigations of Mental Disorders. International Journal of Social Psychiatry, 3, 7-17. https://doi.org/10.1177/002076405700300101

[10] Feldman, R. S. (2009). Discovering the life span. Pearson.

[11] Gray, M., \& Steinberg, L. (1999). Unpacking authoritative Parenting: Reassessing a multidimensional construct. Journal of marriage and the family, 61(3), 574-587. https://doi.org/10.2307/353561

[12] Hurlock, E. B. (1978). Child growth and development. Tata McGraw-Hill.

[13] Jacob, P., \& Seshadri, S. P. (2013). Parenting in children and adolescents with internalizing disorders. Journal of Indian Association for Child and Adolescent Mental Health, 9(4), 136-148. Retrieved from http://www.jiacam.org/0904/reviewoct2013.pdf

[14] Johal, S. K., \& Kaur, K. (2015). Adolescent aggression and parental behaviour: A correlational study. IOSR Journal of Humanities and Social Science, 20(7), 22-27. Retrieved from http://www.iosrjournals.org/iosr-jhss/papers/Vol20-issue7/Version-3/D020732227.pdf

[15] Keller, H., \& Otto, H. (2009). The cultural socialization of emotion regulation during infancy. Journal of Cross-Cultural Psychology, 40(6), 996-1011. https://doi.org/10.1177/0022022109348576

[16] Lansford, J. E., Dodge, K. A., Pettit, G. S., Criss, M. M., Shaw, D. S., \& Bates, J. E. (2009). Trajectories of Physical Discipline: Early Childhood Antecedents and Developmental Outcomes. Child Development, 80(5)1385-1402. https://doi.org/10.1111/j.1467-8624.2009.01340.x

[17] Maccoby, E. E., \& Martin, J. A. (1983). Socialization in the context of the family: Parent-child interaction. In P. M. (Ed.), \& E. M. Hetherington, Handbook of child psychology (Vol. 4, pp. 1-101). New York: Wiley.

[18] Mandelbaum, D. G. (1948). The Family in India. Southwestern Journal of Anthropology, 123-139 https://doi.org/10.1086/soutjanth.4.2.3628707

[19] Natarajan, A. D. (2010). Culture and perceived parenting style: Implications for interpersonal and academic functioning in Indian and American college students (Doctoral dissertation, Miami University), Oxford, OH, USA.

[20] Nimbalkar, A. S., Shukla, V. V., Phatak, A. G., \& Nimbalkar, S. M. (2013). Newborn care practices and health seeking behavior in urban slums and 
villages of Anand, Gujarat. Indian Pediatrics, 50(4), 408-410. https://doi.org/10.1007/s13312-013-0116-y

[21] Pandey, R. C., \& Kumar, K. (2009). Perceived parental rearing style and personality among Khasi adolescents. Journal of Indian Academy of Applied Psychology, 35, 5760.

[22] Pika, A. (1961). Children's attitudes toward rational versus inhibiting parental authority. The Journal of Abnormal and Social Psychology, 62(2), 315-321. https://doi.org/10.1037/h0044540

[23] Rao, N., McHale, J. P., \& Pearson, E. (2003). Links between socialization goals and child-rearing practices in Chinese and Indian mothers: Infant and child development. An International Journal of Research and Practice, 12(5), 475-492. https://doi.org/10.1002/icd.341

[24] Sachdeva, N., \& Misra, G. (2008). The Changing Images of Parenting in the Three Subcultures of India. Journal of the Indian Academy of Applied Psychology, 16-23.

[25] Sahithya, B. R., Manohari, S. M., \& Vijaya, R. (2019). Parenting styles and its impact on children - a cross cultural review with a focus on India. Mental Health, Religion \& Culture, 22(4), 357-383

[26] Santrock, J. W. (2006). Life Span Development. Mc Graw Hills. https://doi.org/10.1016/b978-0-12$\underline{155140-7.50017-6}$

[27] Shalini, A., \& Acharya, Y. (2013). Perceived paternal parenting style on emotional intelligence of adolescents. Guru Journal of Behavioral and Social Sciences, 1(4), 194-202.

[28] Schaffer, H. R. (1996). Social Development. Oxford: Blackwell Publishers. https://doi.org/10.1080/13698039808404692

[29] Sinha, D. (1981). Socialization of the Indian Child. New Delhi: Concept Publishing Company.

[30] Sriram, R. (2019). Fathering in India: Images and Reality. Varodara: Springer. https://doi.org/10.1007/978-981-13-1715-6

(C) 2020 Himani Verma; Licensee ATSK Publishers.

This is an open access article licensed under the terms of the Creative Commons Attribution Non-Commercial License (http://creativecommons.org/licenses/by-nc/3.0/) which permits unrestricted, noncommercial use, distribution and reproduction in any medium, provided the work is properly cited. 